\title{
ПСИХОЛОГИЧЕСКАЯ БЕЗОПАСНОСТЬ ЛИЧНОСТИ В ЭПОХУ ГЛОБАЛИЗАЦИИ
}

Агузумцян Р. В. (Ереванский Государственный Университет, Ереван, РА)

rvaghuzumtsyan@list.ru

Мурадян Е. Б. (Ереванский Государственный Университет, Ереван, РА)

yelena.muradyan@ysu.am

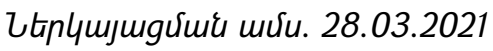

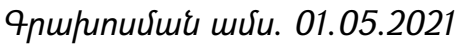

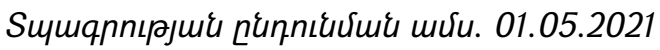

В статье рассматривается проблема психологической безопасности личности в связи с процессом глобализации. Предпринимается попытка выявить взаимосвязь между процессами унификации и интеграции (как маркерами глобализации) и их воздействие на личность. Уделяется внимание вопросу о направленности мировоззренческой "трансформации” личности. В рамках глобализации рассматривается ситуация пандемии, отмечается ее негативное воздействие на человека. Обращается внимание на неизбежность глобализации и ее негативное влияние на психологическую безопасность личности.

DOI: https://doi.org/10.46991/SBMP/2021.4.1.003

Ключевые слова: психологическая безопасность личности, глобализация, унификация, интеграция, “трансформачия” личности.

Понимание безопасности всегда связано с человеком, с субъектом деятельности, с личностью, т.к. в конечном итоге, именно с позиций обеспечения безопасности личности оценивается состояние безопасности государства, функционирования того или иного социального института, производственных объединений, учреждений, учебных заведений и т.д. На наш взгляд, расширение понятия безопасность, благодаря введению такой дефиниции, как “психологическая безопасность личности”, имеет решающее значение для более глубокого с психологической точки зрения осмысления феномена безопасности.

Отмечается, что ведущие исследователи, рассматривающие в качестве общего научного объекта различные формы психологической безопасности, проводя комплексные, междисциплинарные исследования, сосредотачивают внимание на тех сторонах человеческой жизни, на тех внешних и внутренних 
факторах, в которых можно усмотреть риск, опасность, угрозу для человека, т.е. которые могут рассматриваться в качестве причин, детерминирующих возникновение чувства психологического неблагополучия [7]. Риск, опасность, угроза - это основные понятия, используемые при исследовании психологической безопасности личности [13], а практически, это те факторы, отсутствие которых или сведение их к минимому, в каждом отдельном случае или ситуации, позволяют говорить о возможности переживания человеком психологической безопасности.

С этой точки зрения, а именно, возможности переживания человеком психологической безопасности, мы попытаемся рассмотреть процесс глобализации.

Современные тенденции развития мира связаны с таким закономерным, объективным, масштабным социально-экономическим, культурно-политическим, трансформационно-личностным процессом, как глобализация. Этот процесс (в соответствие с законом “перехода количественных изменений в качественные”) обуславливает изменения во всех сферах жизнедеятельности человека по мере вовлечения в этот процесс все большего числа стран. В качестве главных характеристик процесса глобализации, как в содержательном аспекте, так и в процессуальном плане, принято рассматривать унификацию и интеграцию [18].

Под унификацией понимается стереотипизация, стирание различий, “подгонка" к единообразной системе, в то время как интеграция рассматривается как процесс, обеспечивающий возможность объединения, взаимодействия уникальных, обособленных, самостоятельных, разнообразных социальных явлений, связанных с функционированием социальных институтов права, политики, культуры, а если детализировать, то подразумевается охват всех сорер человеческой жизни. Если рассмотреть эти базовые сферы социума с точки зрения оказания влияния на формирование сознания человека, становление личности, то становится очевидным, что главным эфрфектом процесса глобализации являются трансформационные изменения именно личности, ее сознания, ее мировосприятия, ее менталитета, что, несомненно, отражается на переживании человеком собственной психологической безопасности.

С целью более детальной проработки этого утверждения, на наш взгляд, необходимо разобраться в следующих вопросах:

1.Насколько возможно “соприсутствие” или “симбиоз” двух качественно различных процессов: унификации и интеграции как составляющих единый процесс глобализации? 
2.Каким образом, в каком “направлении” происходит трансформация личности, вовлеченной в процесс глобализации с точки зрения формирования ее мировоззренческих позиций, ментальности?

3. Как процесс глобализации влияет на жизнь человека с точки зрения обеспечения ее психологической безопасности?

Попытаемся ответить на первый вопрос, что предполагает необходимость установления возможных связей между понятиями унификации и интеграции. Обращаясь к иследованиям, касающихся процесса глобализации, отметим, что прежде всего речь идет о "единении человечества в целостном мире, взаимодействие внутри такой целостности разнородных и разнообразных национальных, религиозных, государственно-политических компонентов" [11, с. 137-138]. В этом определении можно сразу заметить соприсутствие двух тенденций: с одной стороны, речь идет о единении, о формировании целостности; с другой,- отмечается, что в этой целостности вполне успешно взаимодействуют различные компоненты и, что особенно важно, компоненты принадлежат различным социальным системам! Получается, что создается некая новая социальная система, так сказать, “глобальный мир”, из элементов (компонентов), ранее принадлежащих иным социальным системам, и при этом, находясь в новых связях, обеспечивая формирование новой системы, эти элементы успешно взаимодействуют друг с другом, как бы сохраняя свою уникальность, самобытность и т.д. С точки зрения системного подхода к проблеме, на наш взгляд, такого быть не может, ведь находясь в новых связях, взаимодействуя друг с другом, оказывая влияние друг на друга элементы перестают проявлять те характеристики, которые им были присущи ранее. Взаимодействуя друг с другом, они могут обеспечивать успешное (не имеется в виду оценочный аспект) функционирование новой системы, принадлежат ей и становятся элементами уже совершенно иного, трансформированного социума, а учитывая такой нюанс, что каждый элемент, по-сути, представляет собой также определенную систему, то сохранить собственные уникальные, индивидуальные “черты” ей просто не удастся.

"Трансформация системы - это направленный процесс, который часто скрыт от наблюдателя и реализуется за счет встраивания в ее подсистемные части чужеродных элементов, внешне не разрушающих саму систему, но заставляющих ее работать иным образом" [10, с. 28]. На наш взгляд, если идет процесс унификации, т.е. приведения системы к единому, исключающему разнообразие формату, то сохранение уникальности, самобытности элементов этой системы, как бы противоречит самой сути глобализации. И когда говорят об уравновешивающих друг друга процессах: унификации и интеграции, то хочется привести следующее высказывание: “Процесс глобализации, ведущей тенденцией которого является интеграция мирового сообщества в единое це- 
лое, в результате включает механизмы локальной культурной, национальной дезинтеграции" [10, с. 26].

Исходя из сказанного, возможно рассмотреть процесс унификации в качестве альтернативного процессу интеграции, но не идентичного процессу дезинтеграции, т.к. при унификации создается нечто новое, а в случае дезинтеграции разрушается то, что было.

В то же время, унификацию можно рассмотреть в качестве возможной причины дезинтеграции, а процесс интеграции как вероятность того, что на каком-то этапе он может запустить процесс унификации, тогда как процесс унификации может детерминировать появление нового, уникального, своеобразного.

По-видимому, рассмотрение перечисленных процессов в их потенциально возможных причинно-следственных вариантах взаимодействия, позволит лучше понять природу процесса глобализации.

В связи со сказанным, соотнесенность таких процессов, как интеграция и унификация, на наш взгляд, следует рассматривать в причинно-следственном контексте, а не в пространстве “равнозначных паралеллей”.

Обращаясь к следующему вопросу, о возможных трансформациях личности, попытаемся понять: каким образом и в каком “направлении” (духовнонравственный, мировоззренческий аспект) это происходит.

Процесс глобализации связан с изменениями, происходящими во всех сфрерах жизнедеятельности человека. Если изначально речь шла, в основном, о создании единой мировой экономической системы, то на сегодняшний день можно констатировать глобальные изменения всех сторон человеческой жизни, и самое главное, изменения затронули все “фрормы общественного сознания", их содержательный аспект. Речь идет о системе знаний, мировоззренческих позициях, идеологии, научных концепциях, о системе ценностей, определяющих и формирующих моральные, нравственные, духовные тенденции общества в целом, и каждого отдельного человека, в частности. Практически, происходящие изменения, прежде всего влияют на формирование “содержания” сознания, привнося некоторые изменения в иерархическую последовательность и в “нарратив” мотивационно-потребностной сферы личности.

Непредсказуемость, неопределенность, разнообразие, сложность - все это характеристики современного мира, имеющие тенденцию к нарастанию ...[2]. Эпоха глобальных перемен привносит собственные коррективы и в понимание содержательных характеристик личности, которую можно охарактеризовать как “изменяющуюся личность в изменяющемся мире”, причем “не всегда ясно, изменяющуюся в плане развития, личностного роста или в плане “легкости” смены жизненных принципов, ценностей, идеалов в соответствие с 
современными новообразующимися стандартами жизненных норм" [12, с. 187]. Получается, что более “современное” звучание дефениции может ассоциироваться с менее привлекательным “окрасом” с морально-нравственной и духовной позиций.

В целом, большинство исследователей проблемы глобализации отмечают ряд негативных тенденций в связи с этим процессом в плане воздействия на человека. Так например, говорится о том, что у человека не остается времени на осмысление бытия и происходящих в нем событий, а общечеловеческие ценности часто не воспринимаются людьми как таковые из-за трансорормации или “дефектного” формирования мировоззрения, менталитета. Также отмечается, что процесс глобализации является “благодатной почвой” для развития утилитарного, потребительского отношения к субъектам и объектам окружающей его действительности [15].

Весьма неоднозначно можно интерпретировать влияние процесса глобализации и на формирование толерантности у вовлеченных в этот процесс людей. С одной стороны, процесс способствует актуализации этой позитивной гуманной позиции во взаимоотношениях с другими людьми, так как создает все условия для приобретения опыта толерантного общения в “едином экономическом пространстве”, без которого невозможно было бы эффрективное, плодотворное взаимодействие между людьми, принадлежащих к различным культурам, конфессиям. С другой стороны, унификация, искусственное, навязываемое приобщение человека к новым нормативным формам взаимодействия, могут привести к фрормированию “толерантности к злу и смирению перед ним"[18, с.28]. Возможно, в основе описываемой трансформации лежит тот факт, что в результате процесса унификации запускается процесс дезинтеграции, (например, национальной), происходит растворение отдельных культур в суперкультуре, (часто имеется в виду культура американизированного типа), что оказывает деструктивное воздействие на личность “вплоть до полной потери идентичности с собственной культурой” [10, с. 26].

Все это может приводить к тому, что у человека размываются представления о собственной принадлежности, теряются смыслы, вырабатывается пассивная социальная позиция, он погружается, как бы в “экзистенциальный вакуум” вплоть до потери таких жизненных ориентиров, как представление о добре и зле. Не случайна также и констатация факта дисбаланса, казалось бы, в несопоставимых сфрерах человеческого бытия: “среди составляющих той непомерной социальной цены, которую пришлось заплатить за радикальные экономические реформы в России - пренебрежение нравственно-психологическим миром человека" [4, с. 588]. Звучание этого высказывания весьма резкое, но еще раз подтверждающее факт разрушительного воздействия процесса глобализации на веками формировавшиеся ценности, идеалы, прису- 
щие той или иной культуре, и на основе которых выкристаллизовывались общечеловеческие ценности. Хочется обратить внимание на то, что нивили рование общечеловеческих ценностей как наивысшего достижения человечества в плане гуманизма, происходит, по-видимому, в силу унификации, дезинтеграции, когда объединение людей носит технократический характер и напоминает формирование человеческого сообщества подобного толпе, показатели которой по своим, например, нравственным характеристикам, всегда уступают сумме индивидуальных показателей, входящих в нее субъектов. В результате, иллюзорные представления о гуманизме и демократии в реальности оказываются ни чем иным, как “выражением жажды власти и жестокой технической решимости” [6, с. 490]. В качестве еще одного подтверждения наличия скрытых негативных тенденций процесса глобализации, можно рассмотреть характерное для процесса глобализации “тяготение” к стабильности и сохранению структурно-функциональной специфики уже имеющегося транснационального рынка. И хотя официально декларируется возможность здоровой конкуренции, однако любые попытки “конкурировать”, скорее всего, приведут к серьезным конфликтам, к “жесткому отпору, вплоть до вооруженного вмешательства..." [10, с. 22].

Подобная ситуация никак не напоминает приветствуемый гуманистами сценарий демократического хода развития человеческого сообщества. Высказывается мнение о возможном появлении “Глобальной Империи”, тоталитарной системы нового типа [16]. Практически, каждой стране навязывается определенная роль, выделяется некая “социальная ниша” в глобальном мировом пространстве, а пропагандируемая “стабильность”, которая обеспечит равноценное развитие всех стран, оказывается лишь иллюзией: “Миру навязывается идея: каждая страна должна оставаться в отведенной для нее нише, а это в свою очередь обеспечит стабильность мировой экономический системы и процветание каждой из стран”[10, с. 22]. Получается, что человек оказывается в пространстве “иллюзорной стабильности”, а в реальности становится “ведомым” элементом тоталитарной системы огромных масштабов.

В плане масштабности охвата, в количественном выражении, что обусловлено инновационными технологическими разработками, обращает на себя внимание процесс коммуникации. Причем масштабность коммуникации - это одна из важнейших характеристик и, одновременно, одно из необходимых условий реализации процесса глобализации. Однако, если ранее коммуникационное пространство рассматривалось в качестве условия для диалога культур, то сейчас коммуникация может рассматриваться как самостоятельный, “самодавлеющий” феномен. А формирование коммуникативного пространства на базе одного языка может лишить диалог между культурами всякого смысла: “общение ради общения, общение без насыщения смыслами, 
общение со своим зеркальным отображением по заданным стереотипам коммуникации" [10, с. 30]. Однако изменения в качественном содержании коммуникации и трансформация закономерностей ее течения, - это один аспект проблемы. Другой аспект проблемы видится в рассмотрении глобального коммуникационного пространства в качестве конкретной платорормы; за которую идет (и будет продолжаться) борьба между различными властными структурами. Современный человек, с одной стороны, получает доступ к распространению, получению информации, т.е. приобщается к новейшим технологическим достижениям, но с другой, - становится “объектом” манипулятивного воздействия. Человечество сталкивается с проблемой манипулирования массовым сознанием, с тотальным контролем над каждой личностью, с появлением искусственной виртуальной реальности, которая все больше и больше заменяет человеку реальность бытийно - материальную. Коммуникативное пространство становится реальностью “в определенном смысле не зависящей от человека, но делающей его мир зависящим от нее... Аналогичных процессов в истории человеческого общества не было” [10, с. 27]. Логично предположить, что подобная неопределенность, нестандартность ситуации, связанная с масштабными изменениями, происходящими в обществе, вызывает обеспокоенность будущим человечества, что можно проиллюстрировать следующим высказыванием: “Глобализация пронизывает все уровни общественного сознания, носит агрессивный характер, даже если реализует свои устремления не в виде прямых военных действий” [10, с. 31]. Практически, речь идет об угрозе существованию отдельных государств, их культуры, каждого отдельного человека, индивидуальное сознание, менталитет которого претерпевает значительные изменения под воздействием “общественного сознания".

В связи со сказанным, особую актуальность приобретает вопрос: Как процесс глобализации влияет на жизнь человека с точки зрения обеспечения ее психологической безопасности? Как уже говорилось, обеспечение безопасности рассматривается через призму безопасности личности как главного критерия, на который следует ориентироваться при осуществлении тех или иных мероприятий, направленных на создание соответствующих условий. Психологическая безопасность рассматривается как состояние общественного сознания, при котором общество в целом и каждая отдельная личность, в частности, удовлетворены качеством жизни в настоящем и уверенны в своем будущем [14]. В то же время, предлагается для целостного представления о психологической безопасности личности выделять и рассматривать как бы две стороны этого френомена, две составляющие: внешнюю и внутреннюю. Внешняя связана с достаточно объективными факторами, характеристиками среды, а внутренняя определяется субъективной оценкой личностью среды и соб- 
ственных переживаний в конкретный момент времени [9]. С нашей стороны, проведенное теоретическое исследование по проблеме психологической безопасности личности позволило выявить ряд проблем, а также связь этого феномена с переживаниями и чувствами человека, обусловленных его положением в настоящем и перспективами на будущее [1]. Если следовать логике понимания психологической безопасности личности, то современная ситуация, когда "трансформируются ментальные картины мира людей в условиях "изменения изменений”, нарастания неопределенности, сложности и разнообразия"[2] не способствует переживанию человеком безопасности. Даже те позитивные аспекты процесса глобализации, как например, повышение комфортности жизни человека, часто связаны со снижением уровня защищенности человека в различных сфрерах его жизнедеятельности [10]. Также, ряд исследователей отмечает негативное воздействие процесса глобализации на человека, говоря о возможной “потери идентичности с собственной культурой” [10], о наблюдаемом редуцировании личности в “двоичной цифровой логике трансгуманизма”, о ее (личности) “инвалидизации” и “киборгизации” [5, с. 113-114].

С точки зрения психологической безопасности, привлекает к себе внимание исследование, в котором показана “трансформация” мотивационноценностных приоритетов студенческой молодежи: так, если 17-18 лет назад у молодежи наблюдалась выраженность гражданской, семейной, дружественнокоммуникативной сфер идентичности, то сейчас для молодежи более характерны склонность к индивидуализму, тяготение к интернет-информационному сообществу, проявление деятельностной активности, склонность к самосовершенствованию, стремление к дальнейшему обучению. Также у современной молодежи выявлена тенденция сопричастности с мировым сообществом [8].

В приведенных данных можно усмотреть “зачатки тяготения” молодежи к иной форме культуры, к другому нормативному пространству взаимодействий между людьми, в котором утрачиваются, редуцируются такие ценности, как преемственность поколений, семья, дружба. Более резкие высказывания в отношение “трансформационных изменений” современной молодежи и, в частности, студенчества, как например, следующее: "особенно удручает студенчество, интеллектуальная и культурная деградация которого более чем очевидны” [17, с. 33], преставлены в работе, выполненной в рамках достаточно нового научного направления - "количественной макропсихологии"[7]. Более того, анализ различных аспектов психологической безопасности личности позволяет говорить о возникновении определенных форм асоциального и антисоциального поведения людей под влиянием процесса глобализации[3]. 
Также, в ракурсе нашего исследования, представляет интерес современная ситуация, связанная с пандемией. Мы столкнулись с вовлеченностью в эту ситуацию мирового сообщества, с глобальным характером проблемы. Однако решать проблему каждой стране приходится самостоятельно, а закрытие границ порождает дополнительную “чрезвычайную ситуацию” экономического и психологического характера в глобальном масштабе.

Все сказанное подводит к мысли о негативном воздействии процесса глобализации на человека с точки зрения психологической безопасности. Однако, объективное развитие человеческого сообщества идет по пути глобализации, а уникальное “технологическое сопровождение” этого процесса обеспечивает нарастание темпа такого развития. Человек, “породивший” систему, развивающуюся по пути глобализации, на сегодняшний день, оказался перед фрактом необходимости соответствовать ей с целью успешного функционирования в ней. В этой связи актуальной становится проблема обеспечения психологической безопасности личности в новых условиях, детерминированных процессом глобализации, что, в практическом ключе, связано с формированием такой среды, которая способствовала бы переживанию человеком, в процессе его жизнедеятельности, психологического благополучия и удовлетворенности жизнью.

\section{Литература}

1. Агузумцян Р. В., Мурадян Е. Б. Психологическая безопасность личности как интегративный феномен: теоретический аспект /Актуальные проблемы психологии труда, инженерной психологии и эргономики. Выпуск 6 / под ред. А.А. Обознова, А.Л. Журавлева. - М; Изд-во “Институт психологии РАН”, 2014. - 528с., с. 172 - 188

2. Асмолов А. Г. Психология современности: вызовы неопределенности, сложности и разнообразия // Психологические исследования, 2015, Т.8, N40, (URL: http://psystudy.ru (дата обращения: 25.10.2018))

3. Викторов А .Ш. Введение в социологию безопасности, М.: “Канон”, 2008. - 568c.

4. Гринберг Р. С. Пятнадцать лет рыночной экономики в России //Вестник PAH, 2007, T.77, N7, c. 584-592.

5. Емелин В. А. Технологический радикализм: обратная сторона “цифрового" рая // Личность в эпоху перемен: mobilis in mobili: Материалы международной научно-практической конференции 17-18 декабря 2018 / Под ред. Е. Ю. Патяевой, Е. И. Шлягиной. - М.: Смысл, 2018. - 448 с., с. 112-114.

6. Ерасов Б. С. Сравнительное изучение цивилизаций.- М., М.: АспектПресc, 1998., 536 c. 
7. Журавлев А. Л.,Тарабрина Н. В. Психологичеккая безопасность: на пути к комплексным, междисциплинарным исследованиям (вместо вступления) //Проблема психологической безопасности /Отв.ред. А. Л. Журавлев, Н. В. Тарабрина.- М.: Изд-во “Институт психологии РАН”, 2012. 440 с., с. 5-21.

8. Кондаурова О. П. Эволюция идентичности современного студента // Личность в эпоху перемен: mobilis in mobili: Материалы международной научно-практической конференции 17-18 декабря 2018 / Под ред. Е. Ю. Патяевой, Е. И. Шлягиной. - М.: Смысл, 2018. - 448с.

9. Лебедева Л. Д. Психологическая безопасность личности в арттерапевтической работе/ (https://lib.druzya.org/art-ter/.view-lebedevaart.txt.html (дата обращения:15.03.2021)

10. Миронов В. В. Глобализаиия и угрозы унификаиии / Век глобализаиии 1/ 2012, с.20-33

11. Мнацаканян М. О. Глобализация и национальное государство: три мифа // Социс.- 2004, N5, с.137-142.

12. Мурадян Е. Психологическая трансформация личности в эпоху глобальных перемен и метафорическое пространство сказки // Научный вестник “Актуальная психология”, Ереван 2019, N2 (5), с. 186 - 191.

13. Обеспечение психологической безопасности в образовательном учреждении: практическое руководство /под ред. И. А. Баевой. СПб: Речь, 2006. - 288 с.

14. Рощин С. К., Соснин В. А. Психологическая безопасность:новый подход к безопасности человека, общества и государства// Российский монитор. 1995. N6. с. 133-145.

15. Ручкина Г. Ф. Общество и личность в эпоху перемен: Российская специфика // Сборник материалов Всероссийской научной конференции, Москва: РИПО, 2007, с. 212-219.

http://www.civisbook.ru/files/File/Ruchkina.pd (дата обращения: 11.02.2021)

16. Хардт М., Негри А. Империя / Пер. с англ., под ред. Г. В. Каменской, М. С. Фетисова. - М.: Праксис, 2004.- 440 с.

17. Юревич А. В. Нравственная деградация как угроза национальной безопасности России //Проблема психологической безопасности/Отв.ред. А.Л. Журавлев, Н.В. Тарабрина.- М.: Изд-во “Институт психологии РАН”, 2012.440 c., c.25-46.

18. https://ru.wikipedia.org/wiki/Глобализация, Глобализация Материал из Википедии — свободной энциклопедии (дата обращения:10.02.2021) 


\title{
THE PSYCHOLOGICAL SAFETY OF PERSONALITY IN THE AGE OF GLOBALIZATION
}

Aghuzumtsyan R. V. (YSU, Yerevan, RA) Muradyan Ye. B. (YSU, Yerevan, RA)

The problem of the personality's psychological safety in connection with globalization have considered in this article. An attempt is made to reveal the relationship between the processes of unification and integration (as markers of globalization) and their influence on the personality. Attention is paid to the issue of the direction of the worldview "transformation" of the personality. The situation of the pandemic is considered, its negative impact on humans from the point of view of globalization is noted. Attention is drawn to the inevitability of globalization and its negative impact on the psychological safety of the personality.

Keywords: psychological safety of a person, globalization, unification, integration, "transformation" of a person.

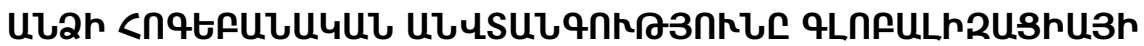 quruzrsuuniv}

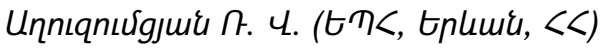

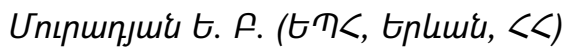

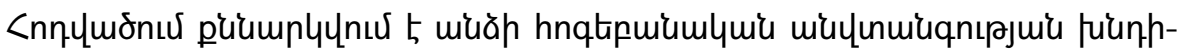

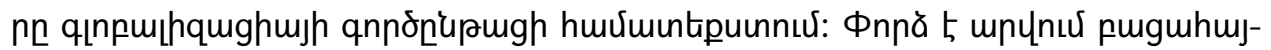

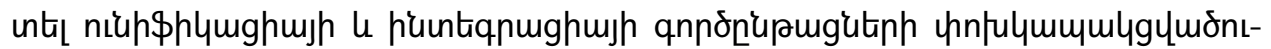

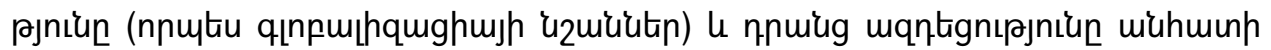

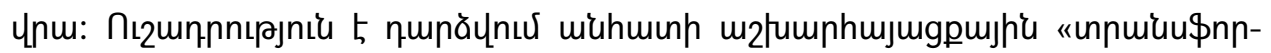

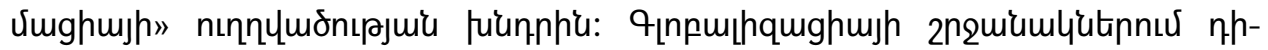

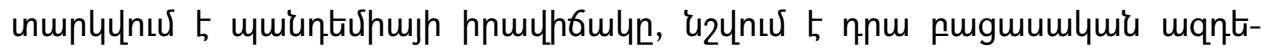

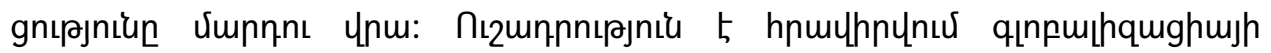

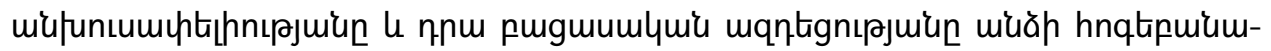

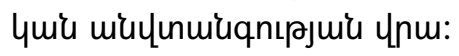

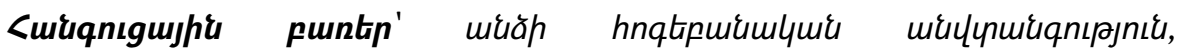

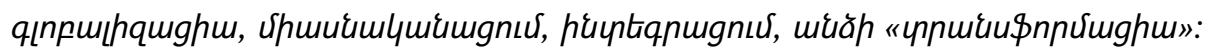

